\title{
Parent's responses to nutrient claims and sports celebrity endorsements on energy-dense and nutrient-poor foods: an experimental study
}

\author{
Helen Dixon ${ }^{1}$, Maree Scully ${ }^{1}$, Melanie Wakefield ${ }^{1, *}$, Bridget Kelly ${ }^{2}$, Kathy Chapman ${ }^{3}$ \\ and Robert Donovan ${ }^{4}$ \\ ${ }^{1}$ Centre for Behavioural Research in Cancer, Cancer Council Victoria, 1 Rathdowne Street, Carlton, Victoria \\ 3053, Australia: ${ }^{2}$ Prevention Research Collaboration, School of Public Health, University of Sydney, Sydney, \\ NSW, Australia: ${ }^{3}$ Cancer Council NSW, Woolloomooloo, NSW, Australia: ${ }^{4}$ Centre for Behavioural Research in \\ Cancer Control, Faculty of Health Sciences, Curtin University, Perth, WA, Australia
}

Submitted 22 April 2010: Accepted 19 November 2010: First published online 10 February 2011

\begin{abstract}
Objective: To assess parents' responses to common, potentially misleading strategies for marketing energy-dense and nutrient-poor (EDNP) child-oriented foods.

Design: Between-subjects online experiment to test whether nutrient claims and sports celebrity endorsements on the front of packs of EDNP products lead parents to prefer and rate these foods more favourably.

Setting: Australia.

Subjects: A total of 1551 parents of children aged 5-12 years, who were the main household grocery buyers.

Results: Inclusion of nutrient claims or sports celebrity endorsements on EDNP products led parents to perceive these products to be more nutritious than if they did not include such promotions. When asked to choose between a pair of different products (EDNP $v$. healthier), $56 \%$ of parents did not read a nutrition information panel (NIP) before making their choice and this did not differ by promotion condition. These parents were more likely to choose an EDNP product if it included a nutrient claim $(\mathrm{OR}=1 \cdot 83,95 \% \mathrm{CI} 1 \cdot 31,2 \cdot 56 ; P<0 \cdot 001)$ or sports celebrity endorsement $(\mathrm{OR}=2 \cdot 37,95 \%$ CI $1 \cdot 70,3 \cdot 32 ; P<0 \cdot 001)$. Sports celebrity endorsements also enhanced parent's perceptions of typical consumers of the product, perceptions of product healthiness and quality, as well as purchase intentions.

Conclusions: Nutrient claims and sports celebrity endorsements tip consumer preferences towards EDNP products bearing such promotions, especially among the majority who do not read the NIP. As parents largely determine what foods are available to children at home, it is critical that initiatives aimed at reducing the persuasive impact of food marketing include this target group.
\end{abstract}

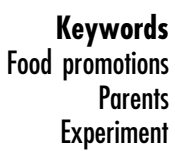

Food marketing techniques have come under scrutiny for their probable contribution to promoting unhealthy eating and childhood obesity ${ }^{(1,2)}$. There is strong evidence that food marketing influences children's food preferences, purchases and consumption ${ }^{(3)}$. However, there is a lack of published data on the impact that marketing of child-oriented foods may have on parents' perceptions of these products and their food purchasing choices.

Parents are important gatekeepers and role models for their children's eating habits ${ }^{(4,5)}$. As the main household grocery buyers, parents influence what foods are available and accessible in the home ${ }^{(6)}$. Recent Australian surveys show that parental concern regarding food advertising and marketing directed at children is high, with the majority of parents in favour of tighter restrictions ${ }^{(7,8)}$. With food companies under increased community pressure to restrict their marketing of energy-dense and nutrient-poor (EDNP) products to children, greater focus has been placed on developing promotions that engage parents and facilitate the purchase of these foods for their children $^{(9)}$.

Research conducted by the British Heart Foundation and UK Food Commission ${ }^{(10)}$ highlights the sophisticated marketing methods used by the food industry in both broadcast (e.g. television) and non-broadcast (e.g. product packaging and company websites) media in order to 
promote EDNP foods to parents. Examples of such marketing techniques include nutrition, health and/or quality claims, endorsement and emotional manipulation. Consumer research indicates that the currently mandated nutrition information panel (NIP) can be confusing ${ }^{(11-13)}$ and difficult to interpret ${ }^{(14)}$. Thus, parents' capacity to make healthy food purchase decisions for their children at the point of sale may be being compromised by these marketing tactics.

Food manufacturers use nutrient claims to emphasise selected positive nutritional attributes of their product and may not give equal prominence to any unhealthy nutritional characteristics in the product. In Australia, there are proposed guidelines regarding the use of nutrient claims on food products ${ }^{(15)}$. However, these do not include disqualifying criteria on the types of foods that can carry these claims based on nutrient profiling, as seen in other jurisdictions such as the European Union ${ }^{(16)}$. Consequently, a confectionery item high in energy and sugar can be marketed as ' $99 \%$ fat-free' if it only contains $1 \%$ fat.

Recent research indicates that the use of nutrient claims in commercial television food advertisements is widespread, appearing most frequently in advertisements for EDNP foods ${ }^{(17)}$. An Australian study on packaged food for sale found that half of the products carried some type of nutrition-related claim and over one-third made at least one nutrient claim ${ }^{(18)}$. Findings from a US study suggest that the presence of nutrient claims on food packages induces consumers to truncate their information search to the front of packages, leading to more positive, quick and misleading summary judgements of products ${ }^{(19)}$.

Associating EDNP foods with physical activity through the use of sports celebrity endorsers is another common food marketing practice. Messages delivered by publicly recognisable sportspeople can contribute to brand name recognition and transfer positive qualities to the brand, such as likeability ${ }^{(20-22)}$. Many leading food companies in Australia and the UK use sport and sports celebrities in their marketing of EDNP food to children ${ }^{(23,24)}$. Qualitative research suggests that the association of particular foods with sport celebrities may influence young people to believe that products high in energy are healthy or enhance sports performance ${ }^{(25)}$. However, empirical research is needed to gauge how parents may be influenced by the presence of sports celebrity endorsements on EDNP food products.

The aim of the present study was to assess parents' responses to common, potentially misleading strategies for marketing EDNP child-oriented foods via food packaging. Specifically, it was hypothesised that the presence of nutrient claims and sports celebrity endorsements on the front of packs of EDNP foods will:

1. lead parents to prefer these food products over healthier food products that do not feature such promotions; and
2. enhance parents' perceptions of these food products compared with EDNP food products that do not feature such promotions.

\section{Method}

\section{Design}

The present study used a three front-of-pack promotion type and five food product category $(3 \times 5)$ betweensubjects experimental design. A web-based method was used to expose parents to one randomly selected EDNP food pack and a comparable healthier food pack. Respondents chose their preferred product to purchase and completed ratings of the EDNP food pack online. Digitally manipulated mock food packs, based on overseas brands and packaging, were used so that responses were not biased by preconceived notions about known Australian market brands. Ethical approval to conduct the present study was obtained from the Cancer Council Victoria Institutional Research Review Committee.

\section{Sample}

A sampling frame of adults who were the main grocery buyers for their household and were the parents/guardians of children aged 5-12 years was sourced from an existing national online panel managed by the market research company commissioned to conduct the fieldwork for the study. Panel members were originally sourced from various methods, including computerassisted telephone interviews, face-to-face and online market research databases.

Eligible panel members were sent an email, with a web link to the survey, inviting them to participate in a study investigating parents' responses to different foods. Respondents were given a chance to win one of ten \$AUD 100 shopping vouchers as an incentive to participate and received points from the market research company upon completing the survey. Three screening questions were asked at the beginning of the survey to confirm that respondents met the eligibility criteria (i.e. parent of 5-12year-old child, main grocery buyer) and were not employed (or had close family/friends) in the food or marketing industries, nor were they dietitians or nutritionists.

\section{Experimental conditions}

Respondents were randomly allocated to view one of fifteen EDNP food pack conditions that varied by frontof-pack promotion type and food product category (see Table 1). The three promotion conditions were: (i) no promotion (control); (ii) nutrient claim; and (iii) sports celebrity endorsement. The nutrient claim promotion condition highlighted a positive nutritional attribute of the product, without reference to its other negative nutritional attributes. The sports celebrity endorsement promotion condition consisted of an image of a popular 


\begin{tabular}{|c|c|c|c|}
\hline \multirow[b]{2}{*}{ Food product category } & \multicolumn{3}{|c|}{ Front-of-pack promotion type } \\
\hline & $\begin{array}{l}\text { No promotion } \\
\text { (control) }\end{array}$ & Nutrient claim & Sports celebrity endorsement \\
\hline Sweetened breakfast cereal & - & Source of fibre & 'A tasty source of fibre to start your kids' day' \\
\hline Cheese dip snacks & - & Source of calcium & 'A great tasting source of calcium for kids on the go' \\
\hline Ice cream bars & - & Reduced fat & ‘Reduced fat Creamsicles are a family winner’ \\
\hline Frozen chicken nuggets & - & Trans fat free & 'Quick, simple and trans fat free. The kids love' em' \\
\hline Flavoured milk drinks & - & Good source of vitamin D & 'A good source of vitamin D and a taste kids adore' \\
\hline
\end{tabular}

Australian sportsperson with a quote attributed to them that contained a nutrient claim and reference to other positive product attributes such as taste and convenience. This format replicates the typical style of sports celebrity endorsements seen on food packaging and in other advertising media. The selected sports celebrities were all parents of children aged 5-12 years, who were not known to have been previously used as an endorser on similar products. A pilot study confirmed that the sports celebrity endorsements were rated by parents as believable, trustworthy and credible.

The five food product categories tested were: sweetened breakfast cereals; cheese dip snacks (savoury); ice cream bars (sweet); frozen chicken nuggets (quick meal); and flavoured milk drinks. Within each food product category, a healthier food pack was prepared, matched on packaging style, to serve as a comparison to the EDNP food packs. Each EDNP food pack contained more kilojoules and higher levels of fat, sugar and/or salt per $100 \mathrm{~g} / 100 \mathrm{ml}$ than their healthier counterparts, and had a nutrient profile that would prohibit them from carrying a health claim under the proposed standard for health claims as determined by the Food Standards Australia New Zealand's (FSANZ) Health Claims Nutrient Profiling Calculator (see http://www. foodstandards.gov.au/consumerinformation/foodlabelling/ nutritionhealthandrelatedclaims/nutrientprofilingcal3499.cfm). An NIP was generated for both food packs on the basis of similar market products. The featured nutrient claims all complied with FSANZ's draft standard $1 \cdot 2 \cdot 7^{(26)}$.

\section{Questionnaire and procedure}

The questionnaire comprised four separate sections:

\section{Product preference: energy-dense and nutrient-poor} food pack v. healthier food pack

Respondents were presented with their randomly assigned EDNP food pack and comparable healthier food pack side by side on screen and asked to choose which one they would be more likely to buy (Fig. 1). Respondents were instructed to click on the product image if they wanted to view the other side of either of the food packs (i.e. they were not explicitly told that this would reveal the product NIP). The order of presentation of the two packs on screen was counterbalanced across respondents.

\section{Perceptions of energy-dense and nutrient-poor food products}

Respondents completed detailed ratings of their perceptions of their assigned EDNP food pack using 7-point Likert scales. Items were adapted from previous research assessing consumer responses to packaging and promotions for food and cigarettes ${ }^{(27-30)}$, and pilot tested on 116 parents to determine their suitability. Questions comprising multiple items were presented randomly to avoid order effects.

To gauge perceptions of the nutritional properties of the EDNP food product, respondents were asked to indicate whether they considered it to contain low (' 1 ') or high ('7') levels of ten nutrients, one of which was the specific nutrient featured on the front of packs of their food product category in the nutrient claim promotion condition (i.e. the target nutrient of the product). Responses were coded according to the extent that they were in line with the specific nutrient claim. For example, for parents assigned to view frozen chicken nuggets in which the nutrient claim was 'trans fat free', scores represented the extent to which parents perceived the product to contain low amounts of trans fats. On the other hand, for parents viewing flavoured milk in which the nutrient claim was 'good source of vitamin D', it corresponded to the extent to which they perceived the product to contain high amounts of vitamin D. Parents were asked to rate all ten nutrients in order to reduce priming of the specific target nutrient.

Respondents also rated how healthy they considered the product to be (from $1=$ 'not healthy at all' to $7=$ 'very healthy'). To assess perceived attributes of the EDNP food package, respondents were asked to indicate their level of agreement (from $1=$ 'strongly disagree' to $7=$ 'strongly agree') with the following statements: 'This product looks as if it would be...': 'of good quality'; 'tasty'; 'inferior to other brands'; and 'good value for money'. Respondents were also asked to rate typical buyers of the EDNP product on a series of eight bipolar traits (see Table 3). Finally, purchase intentions were assessed by asking all respondents to rate how likely they would be to purchase the product next time they go to the supermarket (from $1=$ 'very unlikely to purchase' to $7=$ 'very likely to purchase'). 


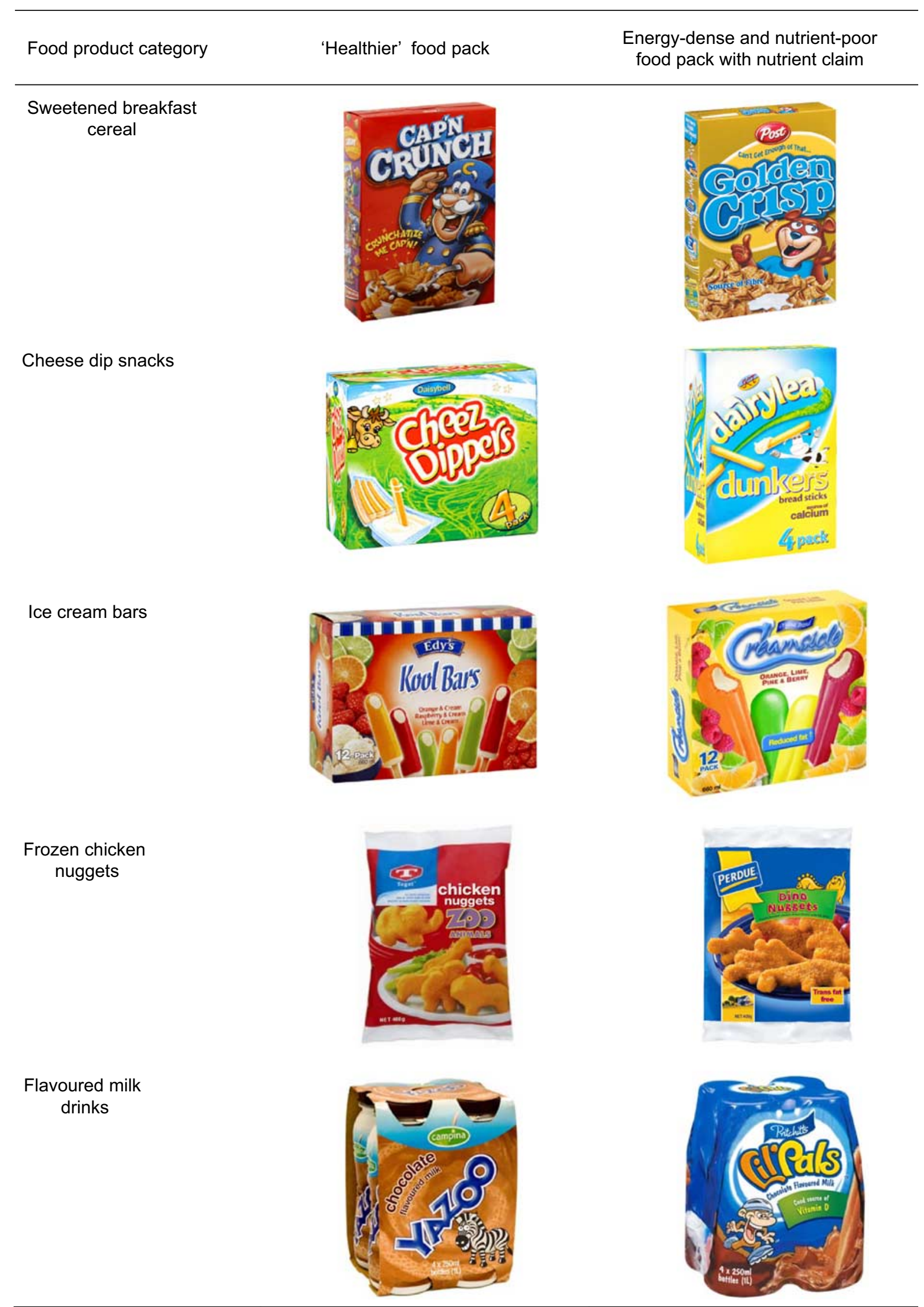

Fig. 1 Example of food packs for nutrient claim promotion condition for each food product category 


\section{Perceptions of healthier food product}

As a manipulation check, respondents were also asked to rate attributes of the comparable healthier food pack they saw at the beginning of the survey and indicate how healthy they considered the product to be.

\section{Demographic and other variables}

After completing these product ratings, respondents were asked to indicate whether they usually read the NIP on food products when at the supermarket, and the extent to which they believe they are knowledgeable about health and nutrition issues. Demographic characteristics such as education level, perceived weight status (of themselves and of child aged between 5 and 12 years) and postcode were recorded. A measure of socio-economic status (SES) was determined according to the urban index of relative advantage/disadvantage as described by the Australian Bureau of Statistics ${ }^{(31)}$, on the basis of respondent's residential postcode. Respondents were considered to be of low SES if they fell within the bottom two quintiles, of moderate SES if their score was in the third or fourth quintile and of high SES if in the fifth quintile.

\section{Statistical analysis}

Data were analysed using the Statistical Package for the Social Sciences statistical software package version $14 \cdot 0$ for Windows (SPSS Inc., Chicago, IL, USA). The $\chi^{2}$ test was carried out to check that random assignment yielded equivalent groups. Logistic regression analysis was conducted to test for differences between promotion conditions on respondent's preference for buying the EDNP product when presented with the product pair.

ANOVA tests were conducted to test for mean differences in ratings of the EDNP product packs by promotion condition. Post hoc $t$ tests with Bonferroni adjustments were used to follow up significant effects. To assess whether education level and NIP reading moderated the effect of promotions on parents' preference for and ratings of the EDNP product, comparisons between high and low education groups and those who did and did not read the NIP at any point before answering each question were conducted as additional exploratory analyses.

\section{Results}

\section{Sample characteristics and group assignment}

Overall, 1551 eligible parents completed the survey, yielding a response rate of $20 \%$ of all sent email invitations. In total, $93 \%$ of respondents were women, $56 \%$ were aged 35-44 years and just over one-third (36\%) had completed tertiary education. About one-quarter (26\%) of respondents were classified as being of low SES, whereas just over one-fifth (22\%) were classified as being of high SES.

Respondents did not differ significantly across promotion conditions in terms of demographic characteristics, their perceived weight status, usual frequency of reading the NIP on food products at the supermarket or knowledge about health and nutrition issues (Table 2). Approximately 517 respondents were allocated to each of the three promotion conditions, with a relatively equal distribution of the five food product types across these three conditions (range: 101-109; data not shown in table).

\section{Manipulation check}

A series of paired sample $t$ tests was conducted to check that the healthier product packs used in the experiment were comparable in terms of brand/pack characteristics to the EDNP product packs bearing no promotion. No significant differences were observed in parents' ratings of the quality, taste, value for money and inferiority to other brands for the EDNP and healthier product packs (all $P>0 \cdot 05$ ). As intended, the healthier food pack was rated as healthier by parents compared with the EDNP food pack $(t=-10 \cdot 36, P<0 \cdot 001)$.

\section{Preference for buying energy-dense and nutrient- poor product (bypotbesis 1)}

Overall, $34 \%$ of respondents indicated a preference for buying the EDNP product over the healthier product when prompted to choose between their product pair. Compared with those in the control condition (29\%), parents exposed to nutrient claims (36\%; OR $=1 \cdot 38 ; 95 \%$ CI $1 \cdot 06,1 \cdot 80 ; P=0 \cdot 016)$ and sports celebrity endorsements $(39 \%$; OR $=1 \cdot 61 ; 95 \%$ CI $1 \cdot 24,2 \cdot 08 ; P<0 \cdot 001)$ were more likely to prefer the EDNP product.

Overall, $56 \%$ of respondents did not click to view an NIP before making their choice and this did not vary by promotion condition. As illustrated in Fig. 2, parents who did not read either NIP were more likely to choose the EDNP product than those parents who had read at least one NIP. Among those who did not read either NIP, there was a significant promotion effect, with parents exposed to nutrient claims (OR $=1 \cdot 83, \quad 95 \%$ CI $1.31,2 \cdot 56 ; P<0 \cdot 001)$ and sports celebrity endorsements $(\mathrm{OR}=2 \cdot 37,95 \%$ CI $1.70,3.32 ; P<0.001)$ more likely to choose the EDNP product than parents in the control condition. There was no effect of the presence of nutrient claims $(\mathrm{OR}=0 \cdot 67,95 \% \mathrm{CI} 0 \cdot 41,1 \cdot 11 ; P=0 \cdot 122)$ or sports celebrity endorsements $(\mathrm{OR}=0 \cdot 68,95 \%$ CI $0 \cdot 42,1 \cdot 13$; $P=0 \cdot 135)$ on the $44 \%$ of parents who had read at least one NIP.

For both education groups, parents were more likely to choose the EDNP product if the pack featured a sports celebrity endorsement (low education: $\mathrm{OR}=1 \cdot 52$, 95\% CI $1 \cdot 10,2 \cdot 10 ; P=0 \cdot 011$; high education: $\mathrm{OR}=1 \cdot 77,95 \%$ CI $1 \cdot 15,2 \cdot 75 ; P=0 \cdot 010)$. The presence of nutrient claims increased the likelihood of parents choosing the EDNP product for the high education group only (OR $=1 \cdot 75,95 \%$ CI $1 \cdot 14,2 \cdot 70 ; P=0 \cdot 010)$. 
Table 2 Demographic characteristics of participants by promotion condition

\begin{tabular}{|c|c|c|c|c|c|}
\hline & \multirow[b]{2}{*}{$\begin{array}{c}\text { Total } \\
(n \text { 1551) }\end{array}$} & \multicolumn{3}{|c|}{ Promotion condition } & \multirow[b]{2}{*}{$P\left(\chi^{2}\right)$} \\
\hline & & $\begin{array}{l}\text { No promotion } \\
\text { (control; } n \text { 517) }\end{array}$ & $\begin{array}{l}\text { Nutrient claim } \\
\quad(n 516)\end{array}$ & $\begin{array}{c}\text { Sports celebrity } \\
\text { endorsement }(n 518)\end{array}$ & \\
\hline Sex & & & & & 0.776 \\
\hline Male & $6 \cdot 8$ & $6 \cdot 2$ & $7 \cdot 2$ & $7 \cdot 1$ & \\
\hline Female & $93 \cdot 2$ & $93 \cdot 8$ & $92 \cdot 8$ & $92 \cdot 9$ & \\
\hline Age group (years) & & & & & $0 \cdot 218$ \\
\hline $18-34$ & $25 \cdot 9$ & $24 \cdot 4$ & $25 \cdot 4$ & $27 \cdot 8$ & \\
\hline $35-44$ & $55 \cdot 6$ & $54 \cdot 2$ & $57 \cdot 9$ & $54 \cdot 8$ & \\
\hline$\geq 45$ & $18 \cdot 5$ & $21 \cdot 5$ & $16 \cdot 7$ & $17 \cdot 4$ & \\
\hline Education level & & & & & 0.555 \\
\hline Did not complete tertiary (low) & $63 \cdot 9$ & $64 \cdot 0$ & $62 \cdot 2$ & $65 \cdot 4$ & \\
\hline Completed tertiary (high) & $36 \cdot 1$ & $36 \cdot 0$ & $37 \cdot \overline{8}$ & $34 \cdot 6$ & \\
\hline SES & & & & & 0.449 \\
\hline Low & $26 \cdot 1$ & $27 \cdot 3$ & $26 \cdot 0$ & $25 \cdot 0$ & \\
\hline Medium & $52 \cdot 2$ & $53 \cdot 6$ & $50 \cdot 3$ & $52 \cdot 6$ & \\
\hline High & $21 \cdot 7$ & $19 \cdot 1$ & $23 \cdot 7$ & $22 \cdot 3$ & \\
\hline Number of children aged $5-12$ years & & & & & 0.296 \\
\hline 1 & $52 \cdot 9$ & $52 \cdot 6$ & $50 \cdot 6$ & $55 \cdot 4$ & \\
\hline$\geq 2$ & $47 \cdot 1$ & $47 \cdot 4$ & $49 \cdot 4$ & $44 \cdot 6$ & \\
\hline Perceived weight & & & & & 0.580 \\
\hline Underweight & $14 \cdot 4$ & $13 \cdot 3$ & $15 \cdot 5$ & $14 \cdot 3$ & \\
\hline About right weight & $75 \cdot 9$ & $76 \cdot 0$ & $74 \cdot 2$ & $77 \cdot 4$ & \\
\hline Overweight & $9 \cdot 7$ & $10 \cdot 6$ & $10 \cdot 3$ & $8 \cdot 3$ & \\
\hline Usual frequency of reading NIP & & & & & 0.603 \\
\hline Never/rarely & $14 \cdot 8$ & $15 \cdot 3$ & $14 \cdot 3$ & $14 \cdot 7$ & \\
\hline Occasionally & $34 \cdot 8$ & $35 \cdot 0$ & $32 \cdot 6$ & $36 \cdot 9$ & \\
\hline Often & $50 \cdot 4$ & $49 \cdot 7$ & $53 \cdot 1$ & $48 \cdot 5$ & \\
\hline Knowledgeable about health/nutrition & & & & & 0.468 \\
\hline Agree & $66 \cdot 8$ & $68 \cdot 9$ & $65 \cdot 5$ & $66 \cdot 0$ & \\
\hline Not agree & $33 \cdot 2$ & $31 \cdot 1$ & $34 \cdot 5$ & $34 \cdot 0$ & \\
\hline
\end{tabular}

SES, socio-economic status; NIP, nutrition information panel.

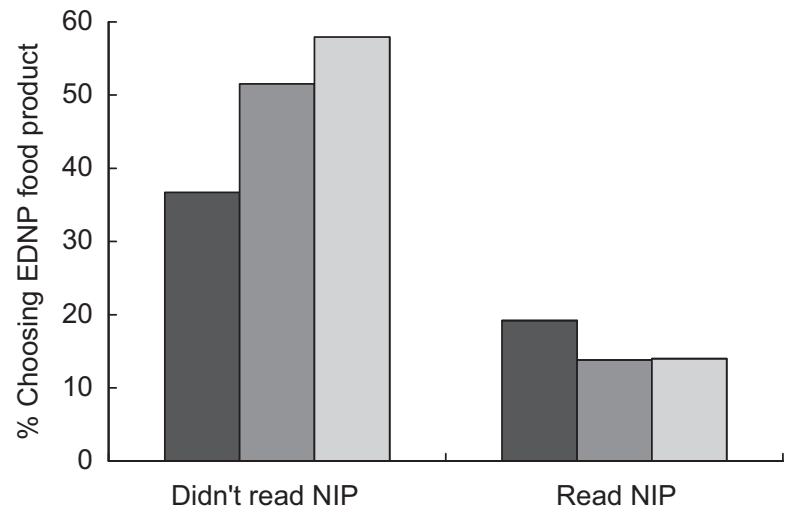

Fig. 2 Parents' preference for choosing to buy the energydense and nutrient-poor (EDNP) food product by promotion condition and nutrition information panel (NIP) reading ( $\square$, control; $\square$, nutrient claim; $\square$, sports celebrity)

\section{Perceptions of energy-dense and nutrient-poor product (bypotbesis 2)}

Table 3 summarises the results of ANOVA tests comparing parents' perceptions of the EDNP product packs by promotion condition.

Parents exposed to both nutrient claims and sports celebrity endorsements perceived quantities of target nutrients in the EDNP foods to be more in the direction indicated by the front-of-pack promotions compared with the control condition (both $P<0 \cdot 001$ ).

Overall, ratings of the perceived healthiness of the EDNP product tended towards the lower end of the scale (mean $=3 \cdot 32$, SD 1.34). However, parents exposed to sports celebrity endorsements rated the unhealthy product as healthier than did parents in the control condition (mean $=3.53 v .3 \cdot 16, P<0 \cdot 001)$.

All EDNP product packs were rated similarly on taste, value and inferiority to other brands regardless of the promotional manipulation. Parents exposed to sports celebrity endorsements perceived their product to be of better quality than did parents in the control condition $(P=0 \cdot 005)$; however, the actual difference between mean values was small.

Parents' perceptions of typical consumers who buy these products were slightly affected by the presence of sports celebrity endorsements. Specifically, those buying sports celebrity endorsed products were perceived as healthier, fitter, more responsible (all $P<0 \cdot 001$ ), richer $(P=0.003)$ and more intelligent $(P=0 \cdot 020)$ than those buying products featuring no promotion. Ratings of typical consumers were similar for products with nutrient claims and with no promotion.

Parents in the sports celebrity endorsement condition expressed stronger intentions for purchasing the EDNP 


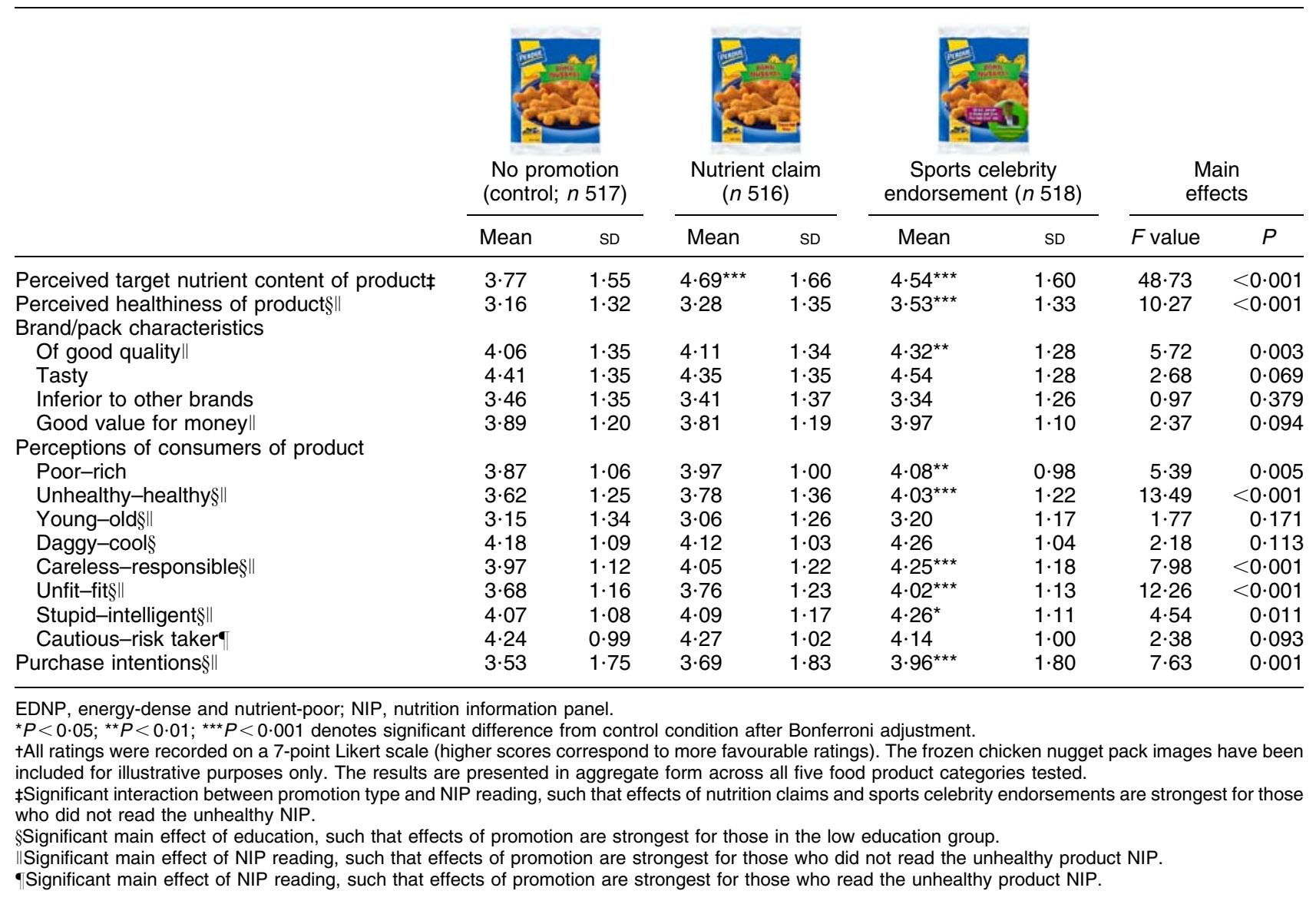

product than did parents in the control condition $(P<0 \cdot 001)$. Exposure to nutrient claims did not increase parents' purchase intentions for the EDNP product compared with the control condition.

\section{Effects of education on ratings}

There were no significant interactions between promotion condition and education for any of the EDNP product ratings. Overall, less-educated parents rated the EDNP product higher in terms of perceived healthiness, and believed typical consumers to be healthier, older and fitter as well as more responsible, intelligent and cool. Less-educated parents also expressed stronger purchase intentions.

\section{Effects of nutrition information panel reading on ratings}

There was a significant interaction between promotion type and NIP reading for perceived target nutrient content, such that promotion effects were strongest for the majority of respondents who did not read the NIP. There were significant main effects of NIP reading for most of the other ratings (see Table 3). Parents who did not read the NIP rated the EDNP product more favourably for all these traits except one (perceived consumer as cautious-risk taker).

\section{Discussion}

The results of the present study suggest that nutrient claims and sports celebrity endorsements influence consumer preferences towards EDNP food products bearing such promotions. The presence of these promotions on EDNP products was also found to lead parents to perceive these products as more nutritious, in line with the frontof-pack promotions. Sports celebrity endorsements also enhanced parents' perceptions of consumers of the product, the healthiness and quality of the product, as well as their purchase intentions. The present study is the first to identify parental responses to these particular forms of food promotions, and finds that parents are influenced by their presence on EDNP child-oriented products.

We found that EDNP food products that did not feature any front-of-pack promotion were most likely to facilitate choice of the healthier product from the product pairs. However, there was also evidence that the persuasive effects of nutrient claims and sports celebrity endorsements on product choice were negated when parents had referred to the NIP. Thus, encouraging consumers to read the NIP at the point of sale may result in parents making healthier food choices for their children. This type of educational strategy is already in operation through 
community programmes such as FOODcents in Western Australia ${ }^{(32)}$. However, a drawback of such community programmes is their reliance on consumer motivation to seek out this information when at the supermarket. As parents are often pressed for time when grocery shopping, particularly when accompanied by their children, it may be unrealistic to expect them to refer to the NIP and make detailed product comparisons. Indeed, even in this less time-pressured experimental situation, where it would have been easy for parents to click on the NIP to help them decide between two unfamiliar brands, only $44 \%$ did so.

From an obesity prevention viewpoint, an ideal policy approach would be to only permit the use of nutrient claims and sports celebrity endorsements on healthy food products that meet set nutritional criteria. Nutrient profiling is proposed for use in Australia to regulate the use of health claims on food products. However, nutrient claims only need to comply with criteria for the specific nutrient that is promoted. Further, there are no regulations regarding sports celebrity endorsements appearing on food packaging. Applying more stringent guidelines to the use of both promotions would minimise the likelihood of parents being misled about a product's nutritional value.

If nutrient claims are to be permitted on EDNP food products, it would be useful for accurate and balanced nutrition information to also be immediately visible on the front of food packages. Currently in Australia, there are a number of front-of-pack labelling schemes that have been developed, with Percentage Daily Intake (\%DI) labelling (modelled on the Guideline Daily Amount system) being the scheme most supported by the food industry. Recent Australian research on the effectiveness of different front-ofpack labelling systems, including \%DI, found that a traffic light system was the most effective in assisting consumers to identify healthier foods ${ }^{(33)}$. Traffic light labelling uses colour coding to indicate whether a product contains low (green), moderate (amber) or high (red) amounts of key nutrients (total fat, saturated fat, sugars and sodium). The UK Food Standards Agency recommends the use of traffic light labelling, a stance that is underpinned by extensive consumer research in this area ${ }^{(34-37)}$. Future research is needed to explore whether traffic light labelling may weaken the effects of front-of-pack promotions.

Some study limitations should be noted. As the present study was conducted online, it was a simulated purchase setting with parents shown 'virtual' packs and asked to make product choices as if they were in the supermarket. Although unable to physically handle the products, parents' ability to compare the product pairs was aided by their side-by-side presentation on screen and the option to click and view the NIP of each product. An important strength of this online method was that it eliminated other potential confounding variables such as price, shelf position and time constraints.

A further limitation of the study was that our sample was sourced from an existing online panel with a consequently low response rate. Thus, our sample may not be representative of the general population of Australian parents of children aged 5-12 years who are the main grocery buyers for their household. Nevertheless, it was broadly similar in profile to a recent population survey of parents of children aged $<14$ years ${ }^{(7)}$. As this was an experimental study, rather than a population survey, obtaining a representative sample was not the primary consideration. The online panel was a simple and inexpensive method of recruiting parents to the study, where they were randomised to experimental conditions. Parents in each promotion condition had a comparable demographic profile, indicating that randomisation was successful, and enabled differences between conditions to be examined.

A strength of our study was that we tested the effects of front-of-pack promotions for five representative food product categories. Further, each food product category had its own distinct nutrient claim and sports celebrity endorsement. This provided confidence that any effects observed were not due to the type of food product, a focus on one specific nutrient or the image of a particular sportsperson.

With calls for greater regulation of food marketing to children intensifying, greater emphasis has been placed on promoting EDNP child-oriented foods to parents ${ }^{(9)}$. This is a trend that has emerged in the UK as a result of restriction on television advertising of EDNP foods to children ${ }^{(38)}$. Although the effects of food advertising on children have been well established ${ }^{(3)}$, our experimental findings show that parents are also susceptible to influence, in this case to nutrient claims and sports celebrity endorsements that appear on the front of packs of EDNP food products. As parents are typically the main grocery buyers of the foods available and accessible to children in the home ${ }^{(6)}$, it is critical that initiatives aimed at reducing the persuasive impact of food marketing include this target group.

\section{Acknowledgements}

The present study was funded by Cancer Council Victoria. No conflict of interest is declared. All authors have contributed to the present paper by being involved in conceiving and designing the study or in analysis and interpretation of data, and in writing and revising the paper. The authors thank I-view who conducted the pilot testing and fieldwork for the present research. They are also grateful to Ms Jane Martin, Obesity Policy Coalition, Cancer Council Victoria, Professor Louise Baur, Weight Management Services, Children's Hospital at Westmead, and Professor David Crawford, Centre for Physical Activity \& Nutrition Research, Deakin University, who provided feedback on the design and methods for the present study.

\section{References}

1. World Health Organization (2003) Diet, Nutrition and the Prevention of Chronic Diseases. WHO Technical Report Series no. 916. Geneva: WHO. 
2. World Health Organization (2007) Marketing Food to Children: Changes in the Global Regulatory Environment 2004-2006. Geneva: WHO.

3. Cairns G, Angus K \& Hastings G (2009) The Extent, Nature and Effects of Food Promotion to Children: A Review of the Evidence to December 2008. Geneva: WHO.

4. Brown R \& Ogden J (2004) Children's eating attitudes and behaviour: a study of the modelling and control theories of parental influence. Health Educ Res 19, 261-271.

5. Campbell KJ, Crawford DA, Salmon J et al. (2007) Associations between the home food environment and obesity-promoting eating behaviours in adolescence. Obesity (Silver Spring) 15, 719-730.

6. Story M, Neumark-Sztainer D \& French S (2002) Individual and environmental influences on adolescent eating behaviours. J Am Diet Assoc 102, Suppl. 3, S40-S51.

7. Morley B, Chapman K, Mehta K et al. (2008) Parental awareness and attitudes about food advertising to children on Australian television. Aust $N Z J$ Public Health 32, 341-347.

8. Kelly B, Chapman K, Hardy LL et al. (2009) Parental awareness and attitudes of food marketing to children: a community attitudes survey of parents in New South Wales, Australia. J Paediatr Child Health 45, 493-497.

9. Lee J (2008) Food advertising shifts focus from kids to parents. Marketing, 8 July.

10. British Heart Foundation, The Food Commission, UK (2008) How parents are being misled: a campaign report on children's food marketing. http://www.childrensfood campaign.net/Reports\%202008/HowParentsarebeingMisled. pdf (accessed November 2009).

11. Byrd-Bredbenner C, Wong C \& Cottee P (2000) Consumer understanding of US and EU nutrition labels. $\mathrm{Br} \mathrm{Food} J$ 102, 615-629.

12. Cowburn G \& Stockley L (2005) Consumer understanding and use of nutrition labelling: a systematic review. Public Health Nutr 8, 21-28.

13. Feunekes GI, Gortemaker IA, Willems AA et al. (2008) Front-of-pack nutrition labelling: testing effectiveness of different nutrition labelling formats front-of-pack in four European countries. Appetite 50, 57-70.

14. Jones G \& Richardson M (2007) An objective examination of consumer perception of nutrition information based on healthiness ratings and eye movements. Public Health Nutr 10, 238-244.

15. Food Standards Australia New Zealand (2008) Final assessment report. Proposal P293 - Nutrition, health and related claims. http://www.foodstandards.gov.au/standardsdevelopment/ proposals/proposalp293nutritionhealthandrelatedclaims/ index.cfm (accessed August 2009).

16. European Food Safety Authority (2008) The setting of nutrient profiles for foods bearing nutrition and health claims pursuant to Article 4 of the Regulation (EC) no. 1924/ 2006 - Scientific opinion of the Panel on Dietetic Products, Nutrition and Allergies. http://www.efsa.europa.eu/cs/ BlobServer/Scientific_Opinion/nda_op_ej644_nutrient $\% 20$ profiles_en,2.pdf (accessed November 2009).

17. Kelly B, Hattersley L, King L et al. (2009) Smoke and mirrors: nutrition content claims used to market unhealthy food. Nutr Diet 66, 62-64.

18. Williams P, Yeatman H, Zakrzewski S et al. (2003) Nutrition and related claims used on packaged Australian foods implications for regulation. Asia Pac J Clin Nutr 12, 138-150.

19. Roe B, Levy A \& Derby B (1999) The impact of health claims on consumer search and product evaluation outcomes: results from FDA experimental data. J Public Pol Marketing 18, 89-105.

20. Kamins M (1989) Celebrity and non-celebrity advertising in a two-sided context. J Advert Res 29, 34-42.

21. Ohanian R (1990) Construction and validation of a scale to measure celebrity endorsers' perceived expertise, trustworthiness, and attractiveness. J Advert 19, 39-52.

22. Charbonneau J \& Garland R (2005) Talent, Looks or Brains? New Zealand advertising practitioners' views on celebrity and athlete endorsers. Marketing Bulletin 16, article 3 .

23. Which? (2006) Food Fables: Exploring Industry Myths on Responsible Food Marketing to Kids. Campaign Report. London: Which?.

24. Centre for Health Initiatives (2007) Food Marketing to Children in Australia. Wollongong: The Cancer Council Australia's Nutrition and Physical Activity Committee.

25. Phillipson L \& Jones SC (2008) 'I eat Milo to make me run faster': how the use of sport in food marketing may influence the food beliefs of young Australians. http:// www.anzmac2008.org/_Proceedings/PDF/S05//Phillipson\%20 \&\%20Jones_S1\%20PS\%20P1.pdf (accessed March 2010).

26. Food Standards Australia New Zealand (2009) Proposal P293 - Nutrition, health and related claims consultation paper for first review. http://www.foodstandards.gov.au/ _srcfiles/P293\%20Health\%20Claims\%20Cons\%20 Paper\%20 FINAL.pdf (accessed August 2009).

27. Wakefield MA, Germain D \& Durkin SJ (2008) How does increasingly plainer cigarette packaging influence adult smokers' perceptions about brand image? An experimental study. Tob Control 17, 416-421.

28. d'Astous A \& Jacob I (2002) Understanding consumer reactions to premium-based promotional offers. EurJ Mark 36, 1270-1286.

29. Andrews JC, Burton S \& Netemeyer RG (2000) Are some comparative nutrition claims misleading? The role of nutrition knowledge, ad claim type and disclosure conditions. J Advert 29, 29-42.

30. Pechmann C \& Shih C-F (1999) Smoking scenes in movies and antismoking advertisements before movies: effects on youth. J Mark 63, 1-13.

31. Australian Bureau of Statistics (2008) Information Paper: An Introduction to Socio-Economic Indexes for Areas (SEIFA) 2006. Catalogue no. 2039.0. Canberra: ABS.

32. FOODcents (2010) Reading food labels. http://www. foodcentsprogram.com.au/about-foodcents/shop-smart/ labels/ (accessed March 2010).

33. Kelly B, Hughes C, Chapman K et al. (2009) Consumer testing of the acceptability and effectiveness of front-ofpack food labelling systems for the Australian grocery market. Health Promot Int 24, 120-129.

34. Malam S, Clegg S, Kirwan S et al. (2009) Comprehension and Use of UK Nutrition Signpost Labelling Schemes. London: UK Food Standards Agency.

35. Food Standards Agency (2005) Qualitative Signpost Labelling Refinement Research. London: Synovate.

36. Food Standards Agency (2005) Quantitative Evaluation of Alternative Food Signposting Concepts. London: Synovate.

37. Food Standards Agency (2004) Concept Testing of Alternative Labelling of Healthy/Less Healthy Foods. Gerrards Cross: Navigator.

38. Ofcom (2008) Changes in the nature and balance of television food advertising to children. A review of HFSS advertising restrictions. http://www.ofcom.org.uk/binaries/ research/tv-research/hfssdec08.pdf (accessed January 2011). 